\title{
Binuclear heterometallic M(III)-Mn(II) (M = Fe, Cr) oxalate-bridged complexes associated with a bisamidinium dication: a structural and magnetic study
}

\author{
Catalin Maxim, ${ }^{\text {a,b }}$ Sylvie Ferlay ${ }^{\mathrm{a}, \mathrm{c}, *}$ and Cyrille Train $^{\mathrm{d}, \mathrm{e}, *}$ \\ 5 Received (in $X X X, X X X) X$ th $X X X X X X X X X 200 X$, Accepted Xth $X X X X X X X X X 200 X$ \\ First published on the web $X$ th $X X X X X X X X X 200 X$ \\ DOI: 10.1039/b000000x
}

Two heterometallic oxalate-bridged dinuclear anions associated with a non $\mathrm{H}$-bond donor bisamidinium cation, leading to compounds of formula (Cat) $\left[\mathrm{Mn}^{\mathrm{II}}\left(\mathrm{H}_{2} \mathrm{O}\right)_{4} \mathrm{M}^{\mathrm{III}}(\mathrm{ox})_{3}\right]_{2} \cdot 6 \mathrm{H}_{2} \mathrm{O}(\mathrm{M}=\mathrm{Fe}$

10 (1) and $\mathrm{Cr}(2)$ ), are presented. Their structural analysis reveals that the anion is the combination of a tris(oxalato)metallate(III) moiety with a tetra(aqua)manganese(II) entity. A 3D H-bonded network is formed between the crystallisation and coordination water molecules and the terminal and bridging oxalate ligands. The exchange interaction between both metal ions mediated by the oxalate bridge is worth $-4.9 \mathrm{~cm}^{-1}$ for $\mathbf{1}$ and $+1.6 \mathrm{~cm}^{-1}$ for $\mathbf{2}\left(\mathcal{H}=-J \mathrm{~S}_{1} \cdot \mathrm{S}_{2}\right)$.

15

\section{Introduction}

With the recent exciting development of coordination polymers,' the understanding of their formation has concentrated recently many interests. In order to elucidate and

20 rationalise this, several model coordination complexes have been synthesised. To illustrate this approach, the family of oxalate-bridged bimetallic compounds, ${ }^{2}$ related to the field of molecular magnetism, ${ }^{3}$ has provided several series of original compounds of various dimensionalities incorporating a large

25 variety of cations. In the field of extended networks (2D or $3 \mathrm{D})$, several examples of magnetic and/or multifunctional bimetallic oxalate-bridged compounds have been discovered : (i) $(6,3)$ bidimensional bimetallic anionic layers hosting a large variety of cationic guests: spin transition complexes,

30 paramagnetic decamethylferrocenium ${ }^{5}$, photochromic molecules, ${ }^{6}$ nonlinear optical (NLO)-active molecules, ${ }^{7}$ organic $\pi$-electron donors, ${ }^{8}$ chiral cations, ${ }^{9}$ etc... and (ii) $(10,3)$ three-dimensionnal bimetallic anionic network ${ }^{10}$, not as versatile as $2 \mathrm{D}$ networks, which can also welcome cationic

35 functional guests, that lead to remarkable physico-chemical properties."

Isolated oxalate-bridged polynuclear complexes have also been intensively studied. ${ }^{12}$ For example, trinuclear anionic complexes have been formed when associated with TTF, ${ }^{13}$

40 redox-active bipyridinium ${ }^{4}$ or polar's cations. The case of dinuclear coordination complexes have been encountered more scarcely. Two dimeric complexes involving the $\left[\mathrm{M}^{\mathrm{III}}(\mathrm{ox})_{3}\right]^{3-}$ anion are reported : they are related to compounds displaying a monodentate coordination mode of

45 the oxalate between metal centers. ${ }^{16}$ A dimeric homometallic compound, where the bis-bidentate coordination mode of oxalate occurs, has also been reported. ${ }^{17}$ Beside this, there are few bimetallic complexes presenting blocking ligands ${ }^{1.19}$ that are used to prevent willingly the formation of extended 50 networks.
In all cases, the formation of bimetallic species is related to the use of counter cations. Cyclic cationic amidinium are good candidates for this approach. They have recently been used for building extended hydrogen bonded (H-bonded) networks ${ }^{20}$ 55 with poly(thiocyanoato)metallate, ${ }^{21}$ poly(oxalato)metallate ${ }^{22}$ or poly(cyanido)metallate. ${ }^{23}$ Some of the reported crystalline H-bonded networks exhibit luminescence ${ }^{24}$, porosity ${ }^{25}$ or liquid crystalline behaviour. ${ }^{26}$ When these cations are not involved in $\mathrm{H}$-bonds with anionic units, the formed 60 compounds can behave as ionic liquids, as recently shown. ${ }^{27}$

Here we report our first efforts to build up oxalate-bridged architectures in association with a dication $\left(\mathrm{Cat}^{2+}\right)$ based on cyclic bisamidinium. Two heterometallic compounds of formula $\mathrm{Cat}\left[\mathrm{Mn}^{\mathrm{II}}\left(\mathrm{H}_{2} \mathrm{O}\right)_{4} \mathrm{M}^{\mathrm{III}}(\mathrm{ox})_{3}\right]_{2} \cdot 6 \mathrm{H}_{2} \mathrm{O}(\mathrm{M}=\mathrm{Fe}(\mathbf{1})$ and $\mathrm{Cr}$ 65 (2)) have been obtained (Scheme 1). They are based on the $\left[\mathrm{M}^{\mathrm{III}}(\mathrm{ox})_{3}\right]^{3-}(\mathrm{M}=\mathrm{Fe}$ and $\mathrm{Cr})$ building block, where oxalate presents a bisbidentate coordination mode towards $\mathrm{Mn}(\mathrm{II})$. Compound $\mathbf{1}$ is the first $\mathrm{Mn}-\mathrm{Fe}$ oxalate-bridged oligonuclear complexes to be reported. This is of importance in the 70 understanding of the exchange interaction in $\mathrm{Mn}-\mathrm{Fe}$ oxalatebridged compounds. The complexes have been characterized from a structural point of view and their magnetic properties have been analysed.

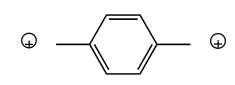

75 Scheme 1: Schematic representation of the used cation (left) and of the obtained anionic bimetallic dinuclear unit with $\mathrm{M}=\mathrm{Fe}$ or $\mathrm{Cr}$ (right).

\section{Results and discussion}

1) Structural analysis 
Compounds $\mathbf{1}$ and $\mathbf{2}$ were obtained as crystalline materials and revealed to be isomorphous (monoclinic, $\mathrm{P} 2_{1} / \mathrm{n}$ ). The asymmetric unit has one half of an amidinium dication lying about an inversion center with one anionic dimeric units $5\left[\left(\mathrm{H}_{2} \mathrm{O}\right)_{4} \mathrm{Mn}^{\mathrm{II}}(\mathrm{ox}) \mathrm{M}^{\mathrm{III}}(\mathrm{ox})_{2}\right]^{-}$and three water molecules in general positions (Fig. 1). A summary of the crystallographic data for $\mathbf{1}$ and $\mathbf{2}$ are listed in Table 1 and selected bond distances and angles for $\mathbf{1}$ and $\mathbf{2}$ are presented in ESI. In the following, since both compounds $\mathbf{1}$ and $\mathbf{2}$ are isomorphous, we 10 will focus on the description of the structure of 1 .

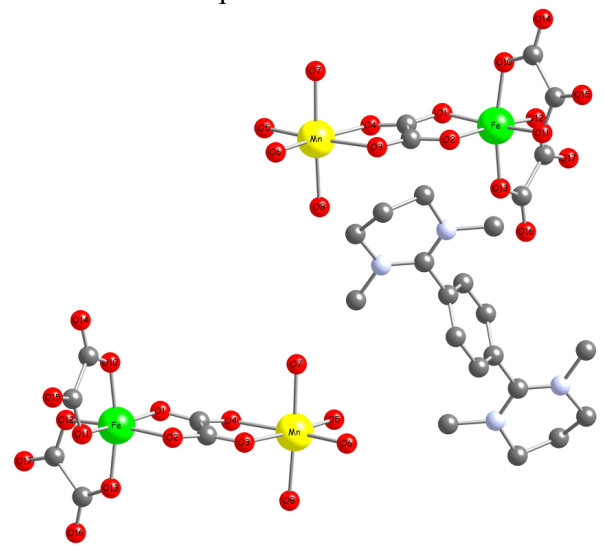

Figure 1 : Dicationic and anionic units in compound 1 together with the numbering scheme.

Table 1 : Crystallographic Parameters for $\mathbf{1}$ and $\mathbf{2}$ recorded at 173K.

\begin{tabular}{ccc}
\hline Formula & $\mathbf{1}$ & $\mathbf{2}$ \\
& $\mathrm{C}_{15} \mathrm{H}_{28} \mathrm{FeMnN}_{2} \mathrm{O}_{19}$ & $\mathrm{C}_{15} \mathrm{H}_{28} \mathrm{CrMnN}_{2} \mathrm{O}_{19}$ \\
Molecular weight & 651.18 & 647.33 \\
Crystal system & Monoclinic & Monoclinic \\
Space group & $\mathrm{P} 2(1) / \mathrm{n}$ & $\mathrm{P} 2(1) / \mathrm{n}$ \\
$\mathrm{a}(\AA)$ & $9.0124(2)$ & $9.0030(2)$ \\
$\mathrm{b}(\AA)$ & $19.4857(4)$ & $19.3913(5)$ \\
$\mathrm{c}(\AA)$ & $14.4710(3)$ & $14.5081(4)$ \\
$\beta(\mathrm{deg})$ & $96.089(1)$ & $96.087(1)$ \\
$\mathrm{V}\left(\AA^{3}\right)$ & $2526.96(9)$ & $2518.54(11)$ \\
$\mathrm{Z}$ & 4 & 4 \\
$\mathrm{Colour}$ & green & violet \\
Crystal dim $\left(\mathrm{mm}^{3}\right)$ & $0.15 \mathrm{x} 0.05 \mathrm{x} 0.05$ & $0.1 \mathrm{x} 0.06 \mathrm{x} 0.03$ \\
$\mathrm{D}_{\text {calc }}\left(\mathrm{gcm}{ }^{-3}\right)$ & 1.712 & 1.707 \\
$\mathrm{~F}(000)$ & 1340 & 1332 \\
$\mu\left(\mathrm{mm}^{-1}\right)$ & 1.165 & 1.024 \\
Wavelength $(\AA)$ & 0.71073 & 0.71073 \\
Number of data meas. & 21357 & 15487 \\
Number of data with $\mathrm{I}>$ & $7379[\mathrm{R}(\mathrm{int})=$ & $4875[\mathrm{R}(\mathrm{int})=0.0416]$ \\
$2_{\sigma(\mathrm{I})}$ & $0.0222]$ & $\mathrm{R} 1=0.0862, \mathrm{wR} 2=$ \\
$\mathrm{R}$ & $\mathrm{R} 1=0.0275, \mathrm{wR} 2=$ & 0.2217 \\
& .0736 & $\mathrm{R} 1=0.0920, \mathrm{wR} 2=$ \\
$\mathrm{R}_{\mathrm{W}}$ & $\mathrm{R} 1=0.0370, \mathrm{wR} 2=$ & 0.2316 \\
& 0.0799 & 1.015 \\
GOF & 0.868 & -0.826 and 1.262 \\
Largest peak in final & -0.335 and 0.504 & \\
difference $\left(\mathrm{e} \AA^{-3}\right)$ & & \\
& &
\end{tabular}

For the anionic $\left[\left(\mathrm{H}_{2} \mathrm{O}\right)_{4} \mathrm{Mn}^{\mathrm{II}}(\mathrm{ox}) \mathrm{M}^{\mathrm{III}}(\mathrm{ox})_{2}\right]^{-}$moiety, both metal centres present a slightly distorted octahedral geometry. The manganese(II) ion presents an O6 environment resulting from four coordinated water molecules and two oxygen atoms from 20 the oxalate bridge. The Mn-O distances vary between $2.1418(11) \AA$ and $2.1656(12) \AA$ for water molecules and $2.2424(11) \AA$ and $2.1325(12) \AA$ for the oxalate bridge. This is typical of the + II oxidation state of manganese. The O-Mn-O angles vary between $75.41(5)$ and $96.84(6)^{\circ}$. The iron(III) ion 25 is surrounded by 3 oxalate ligands. The Fe-O distances vary from $1.9838(11) \AA$ and $2.0179(11) \AA$ These figures are typical of the +III oxidation state of iron. The O-Fe-O angles vary between $80.13(4)^{\circ}$ and $96.35(5)^{\circ}$. The $\mathrm{C}-\mathrm{O}$ distances in the bridging oxalate ligand are equal to $1.2319(17) \AA$ when 30 coordinated to $\mathrm{Mn}(\mathrm{II})$, and to $1.2704(17)$ and $1.2739(17) \AA$ when coordinated to $\mathrm{Fe}(\mathrm{III})$. The $\mathrm{C}-\mathrm{O}$ distance for the terminal oxalate ligands are shorter, varying between $1.2146(19) \AA$ and $1.2238(19) \AA$, which is typical for what is observed in the $\mathrm{K}_{3}\left[\mathrm{Fe}(\mathrm{ox})_{3}\right] .3 \mathrm{H}_{2} \mathrm{O}$ salt. ${ }^{28}$ In the two anionic

35 complexes present in the unit cell, the tris(bischelated)metal centres adopt opposite $(\Lambda)$ and $(\Delta)$ configurations (Fig. 1) in agreement with the observed achiral space group $\mathrm{P} 2 / \mathrm{n}$. The shortest intra- and inter-molecular $\mathrm{M}(\mathrm{III})-\mathrm{Mn}(\mathrm{II})$ distances are respectively $5.524 \AA$ and $6.168 \AA$ for the chromium(III)

40 derivatives and $5.478 \AA$ and $6.166 \AA$ for the iron(III) analog.

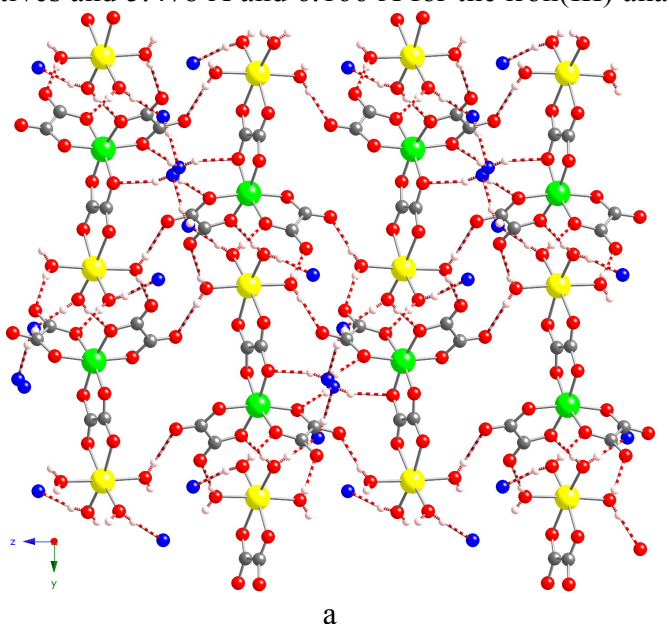

a

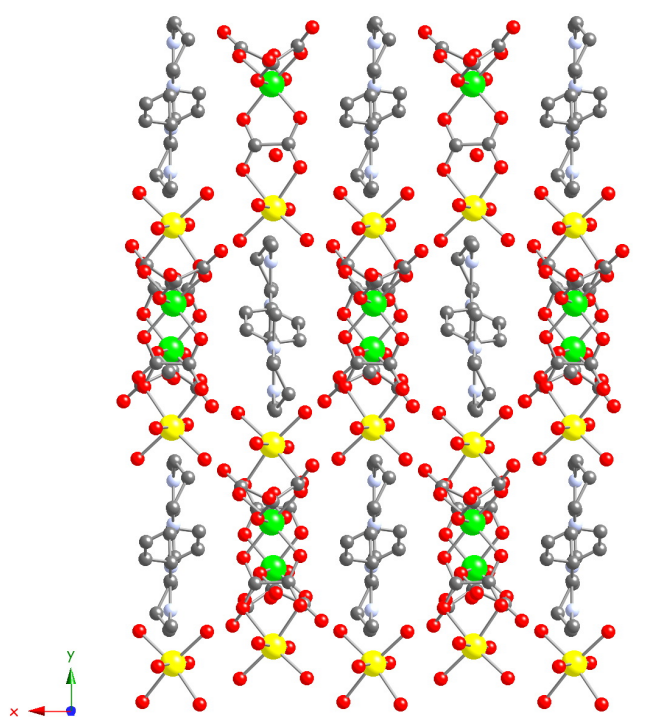

$\mathrm{b}$

45 Figure 2 : For compound 1 a) Role of the water molecules in the formed 3D H-bonded network (red around the Mn atoms and blue for the crystallisation water molecules), view in the (100) plane and b) location of the cationic units, view in the (001) plane

Concerning the cationic moieties, the $\mathrm{C}-\mathrm{N}$ distances vary 
between 1.316(2) $\AA$ and 1.322(2) $\AA$ with the $\mathrm{N}-\mathrm{C}-\mathrm{N}$ angle of $122.38(14)^{\circ}$. These values are close to those observed for analogous $\mathrm{H}$-bond donors bisamidinium compounds. ${ }^{23}$ Both six-member amidinium cycles adopt the usual half chair

5 conformation (Fig. 1) and are almost parallel and tilted with respect to the phenyl ring with the NCCC dihedral angle of $104.9^{\circ}$, which confers to them a twisted conformation inside the cavity.

In the network, the anionic species are interconnected into a

10 3D networks through $\mathrm{H}$-bonds, as shown in figure $2 \mathrm{a}$. All non bonding oxygen atoms of the two terminal oxalate ligands, as well as all oxygen atoms of water molecules surrounding the manganese(II) ion, form H-bonds with O14-O7, O15-O8,

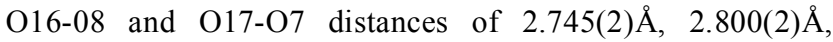

$152.743(2) \AA$ and $2.738(2) \AA$ respectively. The resulting 3D $\mathrm{H}-$ bonded network presents cavities, where some water molecules are located (Fig. 2a). These water molecules are Hbonded to oxygen atoms of bridging oxalate ligands or to coordinated water molecules with $\mathrm{O} \cdots \mathrm{O}$ distances varying

20 from 2.684(3) $\AA$ and 2.931(19) $\AA$. In these cavities are also located the cationic units (Fig. $2 b$ ).

The 3D H-bonded network can be schematized by two non superimposable honeycomb like 2D systems (in the (001) plane) formed by the metals ( $\mathrm{Mn}$ and $\mathrm{Fe}$ ), as shown in figure 253.

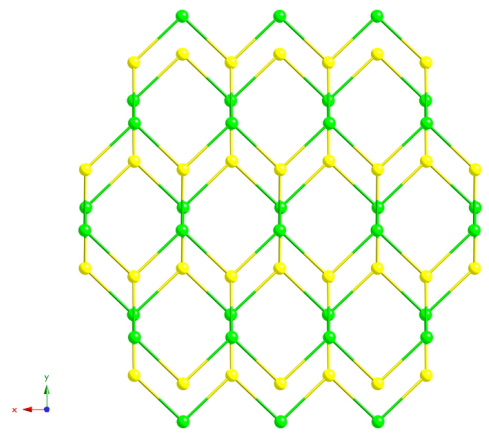

Figure 3 : Projection in the (001) plane of two non superimposable 2D arrays formed by the $\mathrm{Fe}$ (green) and Mn (yellow) metals in $\mathbf{1 .}$

Though a given cation can either lead to a $2 \mathrm{D}$ bimetallic 30 oxalate bridged extended network ${ }^{8}$ or to discrete entities, ${ }^{13}$ it is likely that the counter-ion has some influence on the dimensionality through its size, charge and shape. In the present case, we use a large dication whose characteristics, at first sight, can be considered as comparable to those of NLO-

35 active stilbazolium ${ }^{7}$ or organic $\pi$-electron donors ${ }^{8}$ that lead to the formation of $2 \mathrm{D}(6,3)$ networks. Nevertheless, in the present case, the fact that the used cation may not be engaged in any $\mathrm{H}$-bond with oxalate or solvent molecules, and also a certain flexibility concerning its conformation, influences the

40 formation of the $\left[\left(\mathrm{H}_{2} \mathrm{O}\right)_{4} \mathrm{Mn}^{\mathrm{II}}(\mathrm{ox}) \mathrm{M}^{\mathrm{III}}(\mathrm{ox})_{2}\right]^{-}$dimeric units. A common feature to all the structures containing discrete oxalate-bridged complexes is the presence of numerous $\mathrm{H}$ bonds between the water molecules coordinated to manganese(II) with the terminal oxalate groups of the

45 tris(oxalato)metalate(III) moiety of neighbouring complexes as well as with crystallisation water molecules present in the network (figure 2), leading the formation of a $3 \mathrm{D} \mathrm{H}$-bonded network.

\section{2) Magnetic properties}

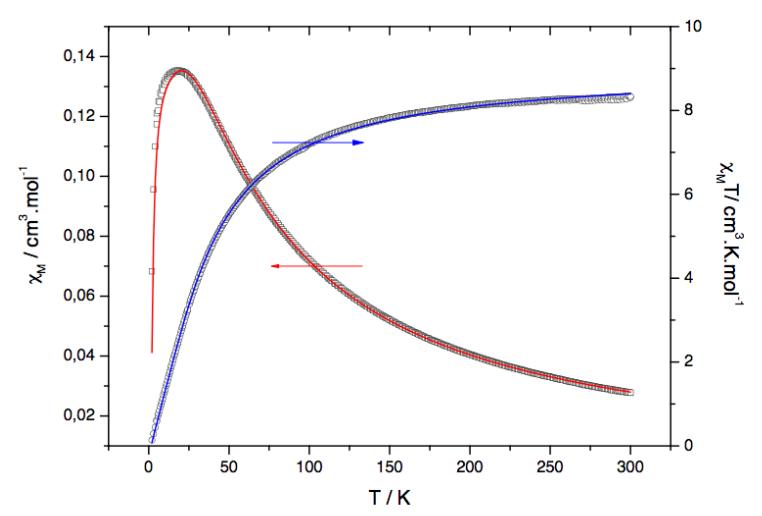

Figure 4 : Thermal variations of the magnetic susceptibility $\chi_{\mathrm{M}}(\square$; left axis) and $\chi_{\mathrm{M}} T$ ( $\mathrm{\circ}$; right axis) product for $\mathbf{1}$, the solid lines being the bestfit curves (see text).

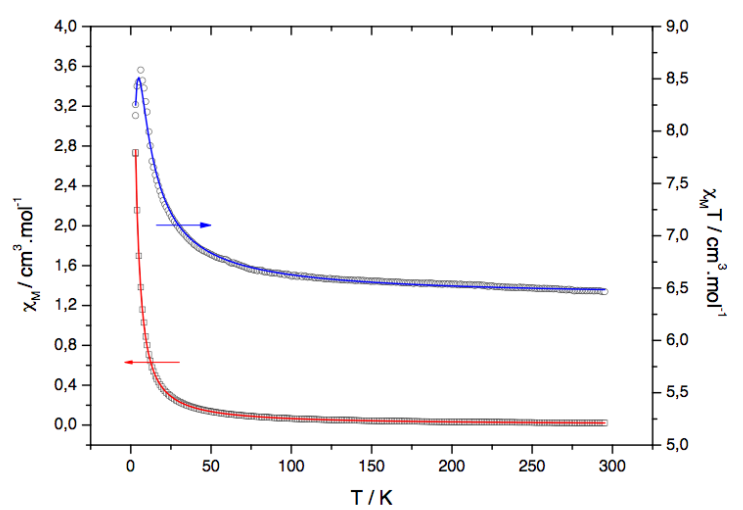

55

Figure 5 : Thermal variations of the magnetic susceptibility $\chi_{\mathrm{M}}(\square$; left axis) and $\chi_{\mathrm{M}} T(\mathrm{\circ}$; right axis) product for 2 , the solid lines being the bestfit curves (see text).

The thermal variations of the molar magnetic susceptibility 60 per dinuclear unit, $\chi_{\mathrm{M}}$, and of the $\chi_{\mathrm{M}} T$ product for $\mathbf{1}$ and $\mathbf{2}$ are shown in figures 4 and 5 respectively. At room temperature (RT), the $\chi_{\mathrm{M}} T$ values are worth 8.34 and $6.46 \mathrm{~cm}^{3} \mathrm{~mol}^{-1} \mathrm{~K}$ for $\mathbf{1}$ and $\mathbf{2}$, respectively. For $\mathbf{1}$, it is slightly lower than the spinonly values $(\mathrm{g}=2)$ expected for the two high spin $\mathrm{S}=5 / 2\left(\chi_{\mathrm{M}} . T\right.$ $65=8.75 \mathrm{~cm}^{3} \cdot \mathrm{K} \cdot \mathrm{mol}^{-1} \mathrm{~cm}^{3} \mathrm{~mol}^{-1} \mathrm{~K}$ ) while, for 2 , it is slightly higher than the value expected for one $\mathrm{S}=3 / 2$ center and one high spin $\mathrm{S}=5 / 2$ center $\left(\chi_{\mathrm{M}} T=6.25 \mathrm{~cm}^{3} \cdot \mathrm{K} \cdot \mathrm{mol}^{-1}\right)$.

When the temperature decreases, the magnetic susceptibility of 1 increases until it reaches a maximum of $c a 0.135$

$70 \mathrm{~cm}^{3} \cdot \mathrm{mol}^{-1}$ at $21 \mathrm{~K}$ and then decreases abruptly. Accordingly, its $\chi_{\mathrm{M}} T$ product displays a monotonous decrease with an increasing rate from RT down to $2 \mathrm{~K}$.

The magnetic behaviour observed for $\mathbf{2}$ is rather different: its magnetic susceptibility increases monotonously with a 75 continuously increasing rate from RT down to $2 \mathrm{~K}$ while its $\chi_{\mathrm{M}} T$ product exhibits a sharp maximum of $8.58 \mathrm{~cm}^{3} \cdot \mathrm{K} \cdot \mathrm{mol}^{-1}$ at $6.2 \mathrm{~K}$ before decreasing abruptly. The overall magnetic behaviour of $\left[\left(\mathrm{H}_{2} \mathrm{O}\right)_{4} \mathrm{Mn}^{\mathrm{II}}(\mathrm{ox}) \mathrm{Fe}^{\mathrm{III}}(\mathrm{ox})_{2}\right]^{-} \quad$ (1) and 
$\left[\left(\mathrm{H}_{2} \mathrm{O}\right)_{4} \mathrm{Mn}^{\mathrm{II}}(\mathrm{ox}) \mathrm{Cr}^{\mathrm{III}}(\mathrm{ox})_{2}\right]^{-} \quad$ (2) is indicative of an antiferromagnetic (AF) and a ferromagnetic (F) exchange interaction between the spin bearers, respectively. Such interactions lead to a $\mathrm{S}=0$ and $\mathrm{S}=3 / 2+5 / 2=4$ ground spin state

5 for 1 and 2 respectively. Accordingly, the $\chi_{\mathrm{M}} T$ product at low temperature falls to 0 for 1 while the maximum value of 8.58 $\mathrm{cm}^{3}$.K. $\mathrm{mol}^{-1}$ observed for $\mathbf{2}$ is lower than the value expected of $10.0 \mathrm{~cm}^{3} \cdot \mathrm{K} \cdot \mathrm{mol}^{-1}$ for a $\mathrm{S}=4$ with $\mathrm{g}=2$. The abrupt decrease below $6.2 \mathrm{~K}$ is indeed the signature of either $\mathrm{AF}$

10 intermolecular interactions or zero field splitting of the $S=4$ ground state. Both phenomena have comparable phenomenological influence on the macroscopic magnetic behaviour of powder samples: they prevent reaching the value expected for an isotropic $\mathrm{S}=4$ ground state. The former

15 phenomenon is arbitrarily favoured through the analysis of the magnetic data.

To provide a quantitative analysis, we describe the system by using an isotropic spin Hamiltonian given by eq. (1.1) for dinuclear complexes. The first term accounts for the

20 intramolecular exchange interaction while the second one treats the intermolecular interactions in the mean field approximation. Eq. (1.1) is used to obtain analytical expressions of the magnetic susceptibility where the second term appears as a correction to the temperature through a 25 Curie-Weiss temperature which is related to the $z j$ by eq. $(1.2) .^{3,18}$

$$
\begin{aligned}
& \mathcal{H}=-J \mathrm{~S}_{\mathrm{Mn}} \cdot \mathrm{S}_{\mathrm{M}}-z j<\mathrm{S}_{\mathrm{z}}>\mathrm{S}_{\mathrm{z}} \\
& \theta=z j S(S+1) / 3 k
\end{aligned}
$$

Table 2 :Best-fit magnetic parameters for 1 and 2

\begin{tabular}{ccccc}
\hline Complex & $J^{a} / \mathrm{cm}^{-1}$ & $\theta^{b} / \mathrm{K}$ & $g^{c}$ & $\Theta$ \\
\hline $\mathbf{1}$ (Mn-Fe) & -4.9 & 0 & 2.02 & $-62^{d}$ \\
2 (Mn-Cr) & +1.6 & -0.67 & 2.21 & $+13^{d}$ \\
{$[$ Mn-Fe] network } & & & & $-86,-146^{31}$ \\
{$[$ Mn-Cr] network } & +0.5 & & & $+6,+9.3^{2,9 \mathrm{a}, 32}$
\end{tabular}

$30{ }^{a}$ Intramolecular magnetic exchange coupling. ${ }^{b}$ Curie-Weiss temperature (see eq. (2.1). ${ }^{c}$ Averaged Landé factor. ${ }^{d}$ Calculated from $J$ using the generalised version of eq. (1.2). ${ }^{18}$

To improve the robustness of the fit, it has been performed simultaneously on the thermal variations of $\chi_{\mathrm{M}}$ and $\chi_{\mathrm{M}} T$

35 product, as shown in Fig. 4 and $5 .^{29}$ The parameters deduced from the fit of the experimental data of $\mathbf{1}$ and $\mathbf{2}$ are summarised in table 2. As anticipated from the qualitative analysis, the intramolecular exchange interaction is $\mathrm{AF}$ for $\mathbf{1}$ and $\mathrm{F}$ for $\mathbf{2}$. Following the $\mathrm{S}=0$ ground state for $\mathbf{1}$, the Curie-

40 Weiss temperature is zero (eq. (1.2)). On the contrary, the negative Curie-Weiss temperature $(-0.67 \mathrm{~K})$ observed for 2 is indicative of AF intermolecular interactions between the $\mathrm{S}=41$ ferromagnetically coupled dinuclear complexes and/or ZFS of the $\mathrm{S}=4$ ground state of these species. The weak 45 intermolecular exchange interactions are mediated by the $\mathrm{H}$ bonds network between the dinuclear complexes. The nature of the exchange observed in 2 corresponds to previously reported experimental results on oxalate-bridged oligonuclear105 Conclusions complexes. $^{15,18}$ Its intensity is slightly higher than the

50 previously reported values. Since $J$ results from the competition between the $\mathrm{F}\left(\mathrm{t}_{2 \mathrm{~g}}\right)^{3}(\mathrm{Cr})-\left(\mathrm{e}_{\mathrm{g}}\right)^{2}(\mathrm{Mn})$ and $\mathrm{AF}$ $\left(t_{2 g}\right)^{3}(\mathrm{Cr})-\left(\mathrm{t}_{2 \mathrm{~g}}\right)^{3}(\mathrm{Mn})$ exchange pathways across the oxalate bridge, ${ }^{30}$ slight modifications of the structure and, hence, of the electronic structure can justify this small increase. Due to 55 the low value of the overall exchange interaction and the existence of competing interactions, we are in borderline cases where sophisticated calculations do not necessarily reproduce the experimental observations ${ }^{15}$ preventing a complete rationalisation of the intramolecular interaction. The $60 \mathrm{AF}$ exchange interaction observed in complex 1 cannot be directly compared to other discrete complexes since there is no previous report on oxalate-bridged oligonuclear [Mn(II)$\mathrm{Fe}(\mathrm{III})]$ complexes. Nevertheless, it is interesting to compare them with [Fe(III)-Fe(III)] oxalate-bridged homometallic 65 dinuclear complexes ${ }^{17 b, e}$ because both have a $d^{5}-d^{5}$ electronic structure. We indeed find here a decrease of the exchange interaction that reaches $25 \%$ compared to the homometallic analogues though the intramolecular metal-metal distance is much comparable. Following the magnetic orbitals analysis 70 introduced by late $\mathrm{O}$. Kahn, ${ }^{3}$ this decrease can be attributed to the mismatch between the energy levels introduced by the heterometallic nature of the complex thus reducing the efficiency of the AF exchange pathways.

A second attractive approach proposed by Ohba et al. consists 75 in comparing the $J$ values obtained for discrete oligonuclear complexes with the Curie-Weiss temperatures found for oxalate-bridged [Mn-M] triconnected extended networks by using the generalised version of eq. (1.2). ${ }^{18}$ Following this procedure, we calculate a value of $-62 \mathrm{~K}$ and $+13 \mathrm{~K}$ for a $(6,3)$

80 network derived from the $J$ values obtained for $\mathbf{1}$ and 2 respectively. The former value is below those observed by Mathonière et $\mathrm{al}^{31}$ for a eight-members series of 2D oxalatebridged [Mn-Fe] networks (Table 2) while the latter is higher than the value observed in [Mn-Cr] networks. ${ }^{2,9 a, 32}$ This

85 discrepancy contrasts with the excellent agreement between the $J$ values of a series of $[\mathrm{M}-\mathrm{Cr}](\mathrm{M}=\mathrm{Mn}, \mathrm{Fe}, \mathrm{Co}, \mathrm{Ni} \mathrm{Cu})$ dinuclear complexes and the Curie temperatures $T_{C}$ of the corresponding 2D networks found by Ohba et al. ${ }^{18} \mathrm{But}$, in their study: (i) the authors compare the $J$ values deduced from

90 a fit using spin Hamiltonians written $-2 J \mathrm{~S}_{1} . \mathrm{S}_{2}$ with a $J_{c a l}$ deduced from $T_{C}$ assuming that the exchange interaction is defined as $-J \mathrm{~S}_{1} . \mathrm{S}_{2} ; J_{c a l}$ is thus overestimated by a factor of 2 (ii) in the mean-field approach the absolute value of the Curie-Weiss $(\Theta)$ and the ordering temperatures $\left(T_{C}\right)$ are equal 95 while a more sophisticated approach leads to $T_{C}<|\Theta|$. This is particularly true for AF coupled networks. It thus appears that the approach proposed by Ohba et al ${ }^{18}$ can only be considered as a rough mean to compare the magnetic properties observed in extended networks and discrete complexes. Nevertheless, it 00 allows (i) to underline the respective role of the exchange parameter $J$ and of the value of the spin of the paramagnetic centres in the $T_{C}$ value (ii) to anticipate from the study of discrete compounds the main trends that can be expected for the related extended networks.

Using a non H-bond donor bisamidiniun dication, two isomorphous oxalate-bridged dinuclear complexes containing a tris(oxalato)metalate(III) moiety in a bis-bidentate 
coordination mode were obtained. Moreover, the structure reveals a $3 \mathrm{D} \mathrm{H}$-bonded network related to the role played by the water molecules. The magnetic properties indicate a AF intramolecular exchange interaction between manganese(II)

5 and iron(III) centers while it is F when the iron(III) is replaced by chromium(III). The absolute intensity of the former is 5 times the one of the latter. In both cases, these properties reflects those observed for analogous extended networks, ${ }^{31,32}$ the role played by the environment (water

10 molecules) being negligeable.

Though it is not the only parameter to control the dimensionality of the formed oxalate bridged bimetallic compound, we intend to ajust the nature (shape, size, charge) of the used amidinium cation to favour the formation of

15 tunable extended networks exhibiting long-range magnetic ordering. This will allow the magnetic properties of the networks with the physico-chemical properties arising from the cation. ${ }^{21-23}$

\section{Experimental part}

\section{Synthesis}

The $\mathrm{MnCl}_{2} \cdot 4 \mathrm{H}_{2} \mathrm{O}$ and $\mathrm{K}_{3}\left[\mathrm{Fe}(\mathrm{ox})_{3}\right] \cdot 3 \mathrm{H}_{2} \mathrm{O}$ were purchased from commercial sources and used as received. $\mathrm{K}_{3}\left[\mathrm{Cr}(\mathrm{ox})_{3}\right] \cdot 3 \mathrm{H}_{2} \mathrm{O}^{33}$ and starting compound $\mathbf{A}$ (Scheme 2 ) were prepared following the literature procedures. ${ }^{23 a, 25}$

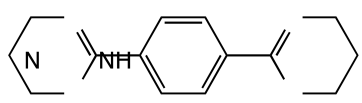

Scheme 2 : Representation of the starting compound $\mathbf{A}$.

\section{Synthesis of cat $^{2+}-2 I^{-}:{ }^{34}$}

A mixture of compound A (1.19 g, $4.92 \mathrm{mmol}), \mathrm{NaH}$ (271 mg, $11.3 \mathrm{mmol})$ in DMF $(100 \mathrm{~mL})$ was stirred at RT. After 2

30 hours, MeI (2.93 g, $20.66 \mathrm{mmol})$ was added to the solution and heated to $75{ }^{\circ} \mathrm{C}$ during 15 hours. The resulting solution was washed with $100 \mathrm{~mL}$ water and with $10 \mathrm{ml} \mathrm{Et}_{2} \mathrm{O}$.

$\mathrm{cat}^{2+}-2 \mathrm{I}^{-}$was obtained in $70 \%$ yield upon recrystallisation from distilled water. $\mathrm{Mp}: 182{ }^{\circ} \mathrm{C}$ (decomposition at $230^{\circ} \mathrm{C}$ ).

$35{ }^{1} \mathrm{H}-\mathrm{NMR}\left(\mathrm{D}_{2} \mathrm{O}, \delta \mathrm{ppm}\right): 2.141$ (q, 4H, $\left.\mathrm{CH}_{2}\left(\mathrm{CH}_{2}-\mathrm{N}\right)_{2}\right), 2.779$ $\left(\mathrm{s}, 12 \mathrm{H}, \mathrm{CH}_{3}-\mathrm{N}\right), 3.502\left(\mathrm{~m}, 8 \mathrm{H}, \mathrm{CH}_{2}-\mathrm{N}\right), 7.631(\mathrm{~s}, 4 \mathrm{H}, \mathrm{CH}$ arom); ${ }^{13} \mathrm{C}-\mathrm{NMR}\left(\mathrm{CD}_{3} \mathrm{OD}, \delta \mathrm{ppm}\right): 22.1\left(\mathrm{~N}-\mathrm{CH}_{2}-\mathrm{CH}_{2}-\mathrm{CH}_{3}-\right.$ $\mathrm{N}), 39.2\left(\mathrm{CH}_{3}-\mathrm{N}\right), 47.7\left(\mathrm{CH}_{2}-\mathrm{N}-\mathrm{CH}_{3}\right), 126.8$ ( $\mathrm{CH}$ arom.), 135.4 ( $\mathrm{CH}$ arom.), $159.0(\mathrm{~N}-\mathrm{C}-\mathrm{N})$. Elemental analysis :

$40 \mathrm{C}_{18} \mathrm{H}_{30} \mathrm{~N}_{4} \mathrm{I}_{2}$ : calculated : $\mathrm{C}=48.13 \%, \mathrm{H}=6.06 \%, \mathrm{~N}=14.03 \%$ ; found: $\mathrm{C}=47.6 \%, \mathrm{H}=5.66 \%, \mathrm{~N}=13.78 \%$.

\section{Synthesis of 1 and 2:}

Compounds 1 and 2 were obtained as green (1) and violet (2) crystals by slow evaporation at room temperature ( 2 weeks) of

45 an aqueous solution $(10 \mathrm{~mL})$ containing $\mathrm{K}_{3}\left[\mathrm{M}(\mathrm{ox})_{3}\right] \cdot 3 \mathrm{H}_{2} \mathrm{O}$ (123 $\mathrm{mg}$ for $\mathrm{M}=\mathrm{Fe}$ and $122 \mathrm{mg}$ for $\mathrm{M}=\mathrm{Cr}, 0.25 \mathrm{mmol}$ ), 10 $\mathrm{MnCl}_{2} \cdot 4 \mathrm{H}_{2} \mathrm{O}(50 \mathrm{mg}, 0.25 \mathrm{mmol})$ and $\mathrm{cat}^{2+}-2 \mathrm{I}^{-}(69 \mathrm{mg}, 0.125$ mmol). Yield : ca. 80\% for 1 and 2.

Elemental analysis for $\mathrm{C}_{15} \mathrm{H}_{28} \mathrm{FeMnN}_{2} \mathrm{O}_{19}$ (1): calculated: $\mathrm{C}=$

$5027.67 \%, \mathrm{H}=4.33 \%, \mathrm{~N}=4.30 \%$; found: $\mathrm{C}=27.55 \%, \mathrm{H}=105$ $4.24 \%, \mathrm{~N}=4.19 \%$; IR: $3423(\mathrm{O}-\mathrm{H}), 3243,3045$ and $2956(\mathrm{C}-$ $\mathrm{H}), 1701,1663,1638(\mathrm{C}-\mathrm{O}) \mathrm{cm}^{-1}$.

Elemental analysis for $\mathrm{C}_{15} \mathrm{H}_{28} \mathrm{CrMnN}_{2} \mathrm{O}_{19}$ (2): calculated: $\mathrm{C}=$
$27.83 \%, \mathrm{H}=4.36 \%, \mathrm{~N}=4.33 \% \%, \mathrm{H} 4.19 \%, \mathrm{~N} 4.21 \%$; IR: $553336(\mathrm{O}-\mathrm{H}), 3045$ and $2925(\mathrm{C}-\mathrm{H}), 1701,1666,1639(\mathrm{C}-\mathrm{O})$ $\mathrm{cm}^{-1}$.

The purity of the obtained polycrystalline samples has been evidenced by PXRD measurements (see fig. S1, ESI). The TGA measurements are also presented in ESI. (see fig. S2, 60 ESI)

\section{Single-Crystal Studies.}

Data were collected at 173(2) K on a Bruker APEX8 CCD Diffractometer equipped with an Oxford Cryosystem liquid $\mathrm{N}_{2}$ device, using graphite-monochromated Mo-Ka $(\lambda=0.71073)$

65 radiation. The structures were solved by direct methods and refined by full-matrix least squares techniques based on $F^{2}$. The non-H atoms were refined with anisotropic displacement parameters. Calculations were performed using SHELX-97 crystallographic software package. All hydrogen atoms were

70 generated geometrically with the exception of the hydrogen atoms of the water molecules. The hydrogen atoms of the water molecules were located on a $\Delta \mathrm{F}$ map and refined with restraints. $^{35}$

CCDC 804356 and CCDC 804357 contain supplementary 75 crystallographic data for 1 and 2 respectively. They can be obtained free of charge from the Cambridge Crystallographic Data Centre via www.ccdc.cam.ac.uk/datarequest/cif.

\section{Physical techniques}

Diagrams were collected on a Bruker D8 diffractometer using 80 monochromatic $\mathrm{Cu}-\mathrm{K} \alpha$ radiation with a scanning range between 3.8 and $30^{\circ}$ using a scan step size of $2 \% \mathrm{mn}$. TGA measurements have been performed on polycrystalline compounds on Pyris 6 TGA Lab System (Perkin-Elmer), using a $\mathrm{N}_{2}$ flow of $20 \mathrm{~mL} / \mathrm{mn}$ and a heat rate of $4{ }^{\circ} \mathrm{C} / \mathrm{mn}$. Variable 85 temperature $(2.0-300 \quad \mathrm{~K})$ magnetic susceptibility measurements were carried out on polycrystalline samples with a MPMS SQUID magnetometer by applying a $1500 \mathrm{G}$ external magnetic field.

\section{Acknowledgement}

90 Pr. M. W. Hosseini is warmly aknowledged for fruitful discussions. This work was supported by the Centre National de la Recherche Scientifique (CNRS), Université de Strasbourg (UdS), Université Joseph Fourier (UJF) and the Agence Nationale de la Recherche (ANR) within the 95 framework of the ANR-08-JCJC-0113-01 project in particular through a postdoctoral grant to $\mathrm{C}$. $\mathrm{M}$.

\section{Notes and references}

${ }^{a}$ Laboratoire de Chimie de Coordination Organique, UMR CNRS-UdS 0 7140, Université de Strasbourg, Institut Le Bel, 4, rue Blaise Pascal, F67000 Strasbourg, France

${ }^{b}$ University of Bucharest, Faculty of Chemistry, Inorganic Chemistry Laboratory, Str. Dumbrava Rosie nr. 23, 020464-Bucharest, Romania. ${ }^{c}$ Institut Universitaire de France (IUF)

$05{ }^{d}$ Laboratoire National des Champs Magnétiques Intenses, UPR CNRS 3228, 25 rue des Martyrs, B.P. 166, 38042 Grenoble cedex 9, France ${ }^{e}$ Université Joseph Fourier, BP 53, F-38041 Grenoble Cedex 9, France E-mail : cyrille.train@grenoble.cnrs.fr,ferlay@unistra.fr 
$\dagger$ Electronic Supplementary Information (ESI) available: PXRD characterization of $\mathbf{1}$ and $\mathbf{2}$, as well as TGA data. Selected bond distances and angles for $\mathbf{1}$ and $\mathbf{2}$.

5 See DOI: $10.1039 / \mathrm{b} 000000 \mathrm{x} /$

1 (a) S. R. Batten and R. Robson, Angew. Chem., Int. Ed., 1998, 37, 1460; (b) A. J. Blake, N. R. Champness, P. Hubberstey, W.-S. Li, M. A. Withersby and M. Schröder, Coord. Chem. Rev., 1999, 183, 117; (c) G. F. Swiegers and T. J. Malefetse, Chem. Rev., 2000, 100, 3483; (d) M. Eddaoudi, D. B. Moler, H. Li, B. Chen, T. M. Reineke, M. O'Keefe and O. M. Yaghi, Acc. Chem. Res., 2001, 34, 319; (e) C. Janiak, Dalton Trans., 2003, 2781; (f) S. Kitagawa, R. Kitaura and S. I. Noro, Angew. Chem., Int. Ed., 2004, 43, 2334; (g) G. Férey, C. Mellot-Draznieks, C. Serre and F. Millange, Acc. Chem. Res., 2005, 38, 217; (h) D. Maspoch, D. Ruiz-Molina and J. Veciana, Chem. Soc. Rev., 2007, 36, 770 .

2 R. Clément, S. Decurtins, M. Gruselle and C. Train, Monatsh. Chem. 2003, 134, 117.

3 O. Kahn, Molecular Magnetism, VCH, New York, 1993.

4 (a) M. Clemente-León, E. Coronado, M. C. Giménez-López, A. Soriano-Portillo, J. C Waerenborgh, F. Delgado and C. Ruiz-Pérez Inorg. Chem. 2008, 47, 9111; (b) M. Clemente-León, E. Coronado, M. López-Jordà, G. Mínguez Espallargas, A. Soriano-Portillo and J. C Waerenborgh Chem. Eur. J. 2010, 16, 2207

5 (a) M. Clemente-León, J. R. Galán-Mascarós and C. J. GómezGarcía, Chem. Commun. 1997, 1727; (b) E. Coronado, J. R. GalánMascarós, C. J. Gómez-García and J. M. Martínez-Agudo, $A d v$. Mater. 1999, 11, 558

6 (a) S. Bénard, P. Yu, J. P. Audière, E. Rivière, R. Clèment, J. Ghilhem, L. Tchertanov and K. Nakatami, J. Am. Chem. Soc. 2000, 122, 9444; (b) S. M. Aldoshin, N. A. Sanina, V. I. Minkin, N. A. Voloshin, V. N. Ikorskii, V. I. Ovcharenko, V. A. Smirnov and N. K. Nagaeva, J. Mol. Struct. 2007, 826, 69.

7 M. Gruselle, B. Malézieux , S. Bénard, C. Train, C. GuyardDuhayon, P. Gredin, K. Tonsuaadu and R. Clément, Tetrahedron Assym. 2004, 15, 3103.

8 (a) M. Kurmoo, A. W. Graham, P. Day, S. J. Coles, M. B. Hursthouse, J. L. Caulfield, J. Singleton, F. L. Pratt and W. Hayes, J. Am. Chem. Soc. 1995, 117, 12209; (b) E. Coronado, J. R. GalánMascarós, C. J. Gómez-García and V. Laukhin, Nature 2000, 408, 447

9 (a) C. Train, R. Gheorghe, V. Krstic, L. M. Chamoreau, N. S. Ovanesyan, G. L. J. A. Rikken, M. Gruselle and M. Verdaguer, Nat. Mater. 2008, 7, 729; (b) C. Train, T. Nuida, R. Gheorghe, M. Gruselle and S.-I. Ohkoshi, J. Am. Chem. Soc. 2009, 131, 16838.

10 (a) S. Decurtins, H. W. Schmalle, P. Schneuwly and H. R. Oswald, Inorg. Chem. 1993, 32, 1888; (b) S. Decurtins, H. W. Schmalle, P. Schneuwly, J. Ensling and P. Gütlich, J. Am. Chem. Soc. 1994, 116, 9521; (c) M. Hernández-Molina, F. Lloret, C. Ruiz-Pérez and M. Julve, Inorg. Chem. 1998, 37, 4141; (d) E. Coronado, J. R. GalánMascarós, C. J. Gómez- García and J. M. Martínez-Agudo, Inorg. Chem. 2001, 40, 113; (e) M. Gruselle, R. Andrés, B. Malézieux, M. Brissard, C. Train and M. Verdaguer, Chirality, 2001, 13, 712; (f) F. Pointillart, C. Train, F. Villain, C. Cartier dit Moulin, P. Gredin, L.M. Chamoreau, M. Gruselle, G. Aullon, S. Alvarez and M. Verdaguer, J. Am. Chem. Soc., 2007, 129, 1327; (g) M. ClementeLeón, E. Coronado, C. J. Gómez-García and A. Soriano-Portillo, Inorg. Chem., 2006, 45, 5653.

11 (a) M. E. von Arx, E. Burattini E, A. Hauser, L. van Pieterson, R. Pellaux and S. Decurtins, J. Phys. Chem. A 2000, 104, 883; (b) R. Sieber, S. Decurtins, H. Stoeckli-Evans, C. Wilson, D. Yufit, J. A. K. Howard, S. C. Capelli and A. Hauser, Chem. Eur. J. 2000, 6, 361.

12 G. Marinescu, M. Andruh, F. Lloret and M. Julve, Coord. Chem. Rev., 2011, 255, 161.

13 (a) E. Coronado, J. R. Galán-Mascarós, C. Giménez-Saiz, C. J. Gómez-García, C. Ruiz-Pérez and S. Triki, Adv. Mater., 1996, 8, 737; (b) E. Coronado, J. R. Galán-Mascarós, C. Giménez-Saiz, C. J. Gómez-García and C. Ruiz-Pérez, Eur. J. Inorg. Chem., 2003, 2290;
14 Y-Q. Sun, J. Zhang, G-Y. Yang, Dalton Trans., 2006, 35, 1685.

15 E. Pardo, C. Train, R. Lescouëzec, K. Boubekeur, E. Ruiz, F. Lloret and M. Verdaguer Dalton Trans., 2010, 39, 4951.

16 (a) O. Costisor, K. Mereiter, M. Julve, F. Lloret, Y. Journaux, W. Linert and M. Andruh Inorg. Chim. Acta, 2001, 324, 352 ; (b) S. Nastase, C. Maxim, F. Tuna, C. Duhayon, J-P. Sutter and M. Andruh Polyhedron, 2009, 28, 1688.

17 (a) V. M. Masters, C. A. Sharrad, P.V. Bernhardt, L. R. Gahan, B. Moubaraki and K. S. Murray, J. Chem. Soc., Dalton Trans., 1998, 413; (b) D. Armentano, G. De Munno, J. Faus, F. Lloret and M. Julve Inorg. Chem. 2001, 40, 655; (c) E. Coronado, J. R. Galán-Mascarós and C. J. Gómez-García, J. Chem. Soc., Dalton Trans., 2000, 205; (d) S. Rachid, S. Turner, P. Day, M. E. Light and M. B. Hursthouse, Inorg. Chem. 2000, 39, 2426; (e) D. Armentano, G. De Munno, F. Lloret, M. Julve M, CrystEngComm, 2005, 7, 57.

18 M. Ohba, H. Tamaki, N. Matsumoto and H. Okawa, Inorg. Chem., 1993, 32, 5385.

19 (a) R. Lescouëzec, G. Marinescu, J. Vaissermann, F. Lloret, J. Faus, M. Andruh and M. Julve, Inorg. Chim. Acta, 2003, 350, 131 ; (b) G. Marinescu, D. Visinescu, A. Cucos, M. Andruh, Y. Journaux, V. Kravtsov, Y. A. Simonov and Janusz Lipkowski Eur. J. Inorg. Chem. 2004, 2914 ; (c) S. Nastase, F. Tuna, C. Maxim, C. A. Muryn, N. Avarvari, R. E. P. Winpenny and M. Andruh Cryst. Gr. \& Des., 2007, 7, 1825.

20 S. Ferlay and M. W. Hosseini in "Functional supramolecular architectures for organic electronics and nanotechnology" Eds. P. Samorì and F. Cacialli, Wiley-VCH, 2010

21 G.Marinescu, S. Ferlay, N. Kyritsakas and M.W. Hosseini, Dalton Trans., 2008, 615.

22 C. Paraschiv, S. Ferlay, N. Kyritsakas, J-M. Planeix and M. Andruh, Rev. Roum. Chim., 2007, 52, 101

23 (a) S. Ferlay, V. Bulach, O. Félix, M. W. Hosseini, J.-M. Planeix and N. Kyritsakas, CrystEngComm, 2002, 447; (b) S. Ferlay, R. Holakovsky, M. W. Hosseini, J.-M. Planeix and N. Kyritsakas, Chem. Comm, 2003, 1224; (c) P. Dechambenoit, S. Ferlay, M. W. Hosseini and N. Kyritsakas, Chem. Commun., 2007, 4626.

24 (a) C. Paraschiv, S. Ferlay, V. Bulach and J-M. Planeix, Chem. Commun., 2004, 2270; (b) P. Dechambenoit, S. Ferlay, N. Kyritsakas and M. W. Hosseini, CrystEngComm., 2011, DOI: 10.1039/c0ce00607f.

25 P. Dechambenoit, S. Ferlay, M. W. Hosseini and N. Kyritsakas, J. Am. Chem. Soc., 2008, 130, 17106.

26 P. Dechambenoit, S. Ferlay, B. Donnio, D. Guillon and M. W. Hosseini, Chem. Commun., 2011, 734.

27 P. Dechambenoit, S. Ferlay, N. Kyritsakas and M. W. Hosseini, New J. Chem., 2010, 34, 1184.

28 R.Wartchow, Z.Kristallogr. 1997, 212, 83.

29 S. Altmannshofer, E. Herdtweck, F. H. Köhler, R. Miller, R. Mölle, E.-W. Scheidt, W. Scherer and C. Train, Chem. Eur. J., 2008, 14, 8013

30 P. Yu, Y. Journaux and O. Kahn, Inorg. Chem. 1989, 28, 100

31 C. Mathonière, C. J. Nuttall, S. G. Carling and P. Day, Inorg. Chem., 1996, 35, 1201 .

32 H. Tamaki,Z. J. Zhong, N. Matsumoto, S. Kida, M. Koikawa, N. Achiwa, Y. Hashimoto and H. Okawa, J. Amer. Chem. Soc. 1992, 114, 6974

33 J. M. Baylar and E. M. Jones in Inorganic Synthesis; Ed: H. S. Booth, McGraw-Hill, New York, 1939.

34 P. Dechambenoit, Ph.D., Université Louis Pasteur, 2008.

35 G. M. Sheldrick, Programs for the Refinement of Crystal Structures, University of Göttingen, Göttingen, Germany, 1996. 